\title{
Research on Thinking Training Path in English Creative Writing Teaching
}

\author{
Juan Jiang \\ Central China Normal University, Wuhan, Hubei, 430070
}

Keywords: College English; creative writing; teaching; thinking training path

\begin{abstract}
At present, the current situation of English writing teaching in colleges and universities in China is not satisfactory. It is still difficult for students to convert accepted language into output language, and students' interest in writing is not high. Although the teacher spends a lot of time and energy in the process of teaching, it has little effect. The traditional college English writing teaching adopts the process method. It emphasizes the writing style planning. The writing process usually includes four stages: pre-writing, drafting, modification and editing. It pays attention to the pre-writing accumulation and creation process, but the process teaching process is long. Due to various objective conditions, it is difficult to implement it in colleges and universities in the medium and long term. Creative writing teaching is an English teaching method that has gradually emerged in China in recent years. As the name suggests, it refers to creative activities in which text creation is the main form and works are the main carrier. The paper discusses the path of students' thinking in English creative writing teaching.
\end{abstract}

\section{Introduction}

Creative writing began in the 1920s. It takes text creation as the main form and uses the works as the main carrier to carry out a series of creative activities. Different from ordinary writing teaching methods, creative writing is similar to the working mode of collective studios. It no longer emphasizes that knowledgeable teaching methods are taught by knowledgeable professors. Instead, teachers and students form a common cooperative group for writing. After completing the creation, I will read my work to other people, and other members of the cooperative group will evaluate it, and propose advantages and disadvantages and revision opinions. Creative writing is very different from traditional writing. Creative writing has no special restrictions on the content and form of the work. It does not require style and number of words. It emphasizes encouraging the full use of imagination in the writing process. Teaching evaluation also adopts diversified The form gives a comprehensive and objective evaluation of the students' works from various aspects. Through the encouragement and guidance of the teachers and the communication and affirmation between the students, the students can experience the fun of writing to the greatest extent, help them establish their writing confidence, and finally guide the students. Enter a virtuous circle and constantly improve your writing skills. It can be seen that creative writing emphasizes the connotation of creativity and highlights the essential distinction between it and traditional writing. Creative writing reflects the characteristics of creativity, practice and commerciality, among which creativity is the first element.

\section{The advantages of creative writing}

Compared with traditional writing teaching, the advantages of English creative writing are mainly reflected in the following aspects:

The motivation of writing determines the attitude of students' writing, and the attitude of writing determines the enthusiasm of students' writing. Therefore, it is very important to stimulate students' writing motivation. Stimulating students' curiosity, establishing their writing confidence, and establishing their sense of writing achievement can improve students' writing motivation. Creative writing can fully explore the potential motivation of students. It respects the free expression of individual thoughts and guides students to discover their own. The inner world encourages its 
expression and is truly student-centered. This teaching method plays a positive role in promoting students' language acquisition and personal growth. Students can be encouraged to use English to create poetry, write stories, create novels, etc., so that students can gain a sense of accomplishment from English writing, and feel the joy of English writing by sharing with others. In addition, language games can be used to create more learning language for students, helping students to find more readers who appreciate their works, and to close the distance between students and students, teachers and students.

Creative writing requires students to freely create and express freely. Students' abilities in vocabulary, grammar and text can be improved to different degrees in the process of writing and expression. Students can acquire language from all levels, thus improving students' overall English. ability. In the process of creative writing, students must use English to create poetry, stories, short plays, etc., and they must express their thoughts and intentions clearly and accurately. Therefore, the process of writing is also the process of improving their ability. In addition, the application of creative writing in the daily teaching of English can guide students to develop good writing habits, bring positive writing motivation, make students more willing to write, and actively write, thus continuously improve their writing ability.

China's new round of education reform emphasizes the cultivation of students' comprehensive quality. Colleges and universities should pay more attention to the improvement of students' comprehensive ability, so that they must not only master modern professional knowledge, but also further improve students' ability to innovate, solve problems and learn. And teamwork capabilities, etc. As mentioned above, creative writing teaching is similar to the working mode of collective studios. Students need to cooperate with others in the process of writing, communicate and discuss together, and then improve and modify their own works. This process improves the teamwork of students. Ability; and creative writing can guide students to creative reading, help develop students' right brain, and further improve students' imagination, creativity, understanding and memory. It can be seen that creative writing helps to improve students' comprehensive ability.

\section{The path of students' thinking cultivation in college English creative writing teaching}

In the actual college English creative writing teaching, the following strategies can be adopted to cultivate students' innovative thinking:

In the process of English literature creation, to some extent, reading is also a kind of creation. By reading English literature, students can learn more about the humanistic tradition of English, gain more ideological resources and creative inspiration, and thus write for students. Create more opportunities. Therefore, in the teaching process, students can be guided and encouraged to read more classic works of English and American literature. Through repeated and intensive reading and analysis of the themes and stylistic features of literary works, the enrichment of ideas can be obtained. To build a poem that can read more English and American classics, the language of poetry is refined, and the theme is profound. Students can stimulate their imagination by realizing the poet's unique image thinking and profound heart inspiration. In the process of English creative writing teaching, students' reading ability is not limited to tangible literary classics, but also includes abstract nature and reading comprehension of life. Therefore, teachers should consciously cultivate students' reading of nature in the teaching process. Understanding ability, guiding them to establish spiritual connection with nature, realizing the poetic fit between man and nature; students' ability to feel nature will have a direct impact on their creative writing, which can be perceived by nature through analogy People fully realize the symbolic meaning and enlightenment of nature in the spiritual category of students, and thus realize the philosophy of life from the appearance of nature, and enhance students' perception of nature and the sensitivity and initiative of life. In addition, we must consciously guide students to strengthen their understanding and perception of life, recognizing that all creations come from life and return to life, draw inspiration and creative materials from real life, broaden the perspective of English writing, and lay down the subsequent English writing. Good ideological foundation and emotional foundation.

Imagination is the basic ability of students to carry out creative writing in English. Literary 
imagination mainly shows two characteristics of purpose and image. The purpose is to have the goal and direction of imagination. It is to imagine under the guidance and control of artistic purpose. Imagery refers to the application of certain image, appearance and imagery factors. English creative writing teaching should pay attention to the cultivation of students' literature imagination. However, literary imagination is different from other imaginations. In addition to relying on image, literary imagination also creates an image or form to create an artistic conception or scene. Literary imagination should focus on typical images, image combinations and post-shaping creations, through which they express their emotions and will. In addition, attention should be paid to the cultivation and improvement of students' language performance ability. Writing practice is the best way for students to integrate writing theory knowledge into literary creation, and also to improve students' language performance ability. This is due to creative writing in English. In the flexible writing practice, whether it is form, length or genre, the writing itself is a kind of experiential learning, and practice is an important way of experience. Language expression can be better obtained through experience. Therefore, teachers should strengthen students' writing practice to help students acquire English vocabulary and grammar knowledge more effectively. In daily teaching, students can be encouraged to try creative writing such as poetry, stories, short plays, etc. When writing, regardless of length, genre, and form, as long as they can accurately and appropriately apply the language, clear and coherent superficial thoughts, to encourage students to actively write, continuously improve their writing skills.

In the 1930s, American literature was in the leading position in the world, and its creative culture industry was also very developed. To some extent, this has a certain correlation with the creative writing disciplines of American colleges and universities. Scientific and effective writing teaching can be Cultivate outstanding writers and prosper creative activities. Although writing is a kind of personal behavior, creators still need to strengthen communication and communication with the outside world in order to obtain more creative materials. Applying writing and teaching teaching mode in English creative writing teaching can provide students with a systematic system. A continuous, natural intellectual reciprocity platform to help students communicate and help each other. In the English creative writing teaching, English creative writing seminars can be set up, and a new mechanism that can exert students' creativity can be established, so that students can gain a sense of pleasure and accomplishment in the process of creation and communication, and stimulate their creative passion and thinking vitality. In the actual teaching process, the teacher should follow the general rules of writing to create a writing plan, and the project or activity will drive the teaching process. Encourage students to read more extracurricularly, and strengthen the training of special skills, such as the skills and training of the works, the collection of materials, the refinement of the theme, the cultivation of images, plot setting, character portrayal and scene description, etc., to further improve the works. In addition, students can be encouraged to contribute actively and publish excellent student works on public platforms such as school newspapers and campus websites to achieve an extension of creative writing.

At present, most of the incumbent English teachers in colleges and universities in China are not good at literary creation, and even many teachers do not even have experience in creating. However, students facing college English, their goal is not to become a writer. English will play the role of a tool in their future academic or career. Therefore, the focus of teaching is not on creation, but on creative writing. To improve students' comprehensive language skills, the requirements for teachers' creation are reduced accordingly. Teachers can enrich their knowledge of literary theory and creation through reading. Many college English majors offer creative writing courses or use related classroom activities. College English teachers can learn from the actual situation of their students.

\section{Conclusion}

In short, creative writing is a new model of college English writing teaching reform. It is known from domestic and foreign teaching experience that creative writing has positive promotion significance for improving students' English writing ability, so it is important in Chinese college English writing teaching. Promote meaning. In the actual creative writing teaching, the teacher 
should carefully design the teaching tasks, highlight the characteristics of creative writing, stimulate students' enthusiasm for learning through interesting and innovative teaching methods; strengthen the cultivation of students' reading comprehension ability, and cultivate students' literary imagination and Language expressiveness provides students with more opportunities for writing practice by offering English creative writing seminars. In addition, teachers must constantly improve their professional qualities. In summary, English creative writing has greatly improved the initiative of students' writing and stimulated their interest in writing, thus achieving the teaching goal of improving their overall quality.

\section{Acknowledgements}

Fund Project: 2016 Provincial University Teaching Research Project of Hubei University, the title of the project: "Three sets of vehicles" on the general needs of teachers in general English, subject number: 2016082.

\section{References}

[1] Dai Fan. Teaching and Research of Creative Writing at Home and Abroad [J]. Chinese Language, 2017, (14): 223-224.

[2] Lin Lihua. Application of Creative Writing in College English Teaching [J]. Journal of Yangtze University (Social Science Edition), 2012, (39): 109.

[3] Liu Nuoya. Measures to Introduce Creative Writing into English Literature Teaching Class [J]. Journal of Kaifeng Education College, 2015, (35): 41-42.

[4] Ge Hongbing, Xu Daojun. An Outline of the Construction of Creative Writing in China [J]. Exploration and Controversy, 2017, (6): 36-37

[5] Zheng Chao. Write to promote learning, let students write self-confidence and sense of accomplishment [J]. Journal of Guangdong University of Foreign Studies, 2016, (13): 154-155.

[6] Lu Tao. Western Creative Writing and University Writing in China [J]. Journal of Ningbo University (Educational Science Edition), 2013, (35): 204-205 